\title{
Pregnancy Outcome in Diabetic Patients at the University College Hospital, U.C.H., Ibadan
}

\author{
Adesina Oladokun', Christopher O. Aimakhu', Oluwatosin A. Awolude', Oladapo Olayemi' \\ and Joko Adeleye ${ }^{2}$ \\ Departments of 'Obstetrics \& Gynaecology, and ' ${ }^{2}$ Medicine, University College Hospital, Ibadan, Nigeria.
}

\begin{abstract}
Context: Diabetes mellitus is one of the common medical complications in pregnancy, which if not properly controlled, can lead to significant perinatal and maternal morbidity and mortality.

Objective: To determine the incidence of diabetes mellitus in pregnancy in this centre, and to assess the effect of maternal glucose control on the obstetric performance as well as perinatal outcome of pregnant diabetics managed at the University Collage Hospital, Ibadan.

Study Design: A review of the obstetric outcome for 49 diabetic women who delivered at the University College Hospital, U.C.H, Ibadan, Nigeria during a 10 -year period (January, 1991 to December 2000 ) is presented.

Results: The incidence rate of diabetes in pregnancy was 0.74 per 1000 deliveries per year. Most patients $(89.8 \%)$ b ooked for a ntenatal $c$ are a nd delivery in this c entre. G ood control was achieved in $77.6 \%$ of patients and the mean birth weight was $3.37 \pm 1.52 \mathrm{~kg}$. There was no significant difference in the birth weight and fetal outcome if a patient had pre-existing or gestational diabetes. However, the outcome was significantly related to the level of control. With good control there was a better Apgar score at 5 minutes, which was prognostic for fetal outcome. The perinatal mortality rate was $98 / 1000$ births and this was significantly associated with poor control when compared with good control $(p<0.05)$. There was no maternal death.
\end{abstract}

Conclusion: Further improvement in the management is needed. Preconception control, early antenatal booking and good control in pregnancy are strongly advocated as means of achieving good pregnancy outcome.

Key Words: Gestation, Diabetes Mellitus, Perinatal Outcome [Trop J Obstet Gynaecol, 2003, 20: 52-55]

\section{Introduction}

Diabetes mellitus is a metabolic disease that results from absolute or relative deficiency of insulin, manifesting as hyperglycaemia and its attendant complications. It is the most common medical complication of pregnancy ', and glucose is the principal nutrient that the mother supplies to the fetus through the placenta by way of concentrationdependent mechanisms ${ }^{2}$.

Management of the pregnant woman with diabetes continues to present a challenge to the physician, obstetrician and neonatologists. The modern management of diabetes in pregnancy was one of the great medical successes of the last century. Prior to the discovery of insulin in 1921 by Banting and Best in Toronto ${ }^{3}$, few diabetic women conceived and, in those who did, pregnancy was disastrous with the mother or infant or both dying. As a result of a team approach to management, improved methods of fetal surveillance and, more recently, an emphasis on strict metabolic control (beginning prior to conception), the perinatal mortality (PNM) has declined in most developed countries to approximately that in the non-diabetic pregnant population ${ }^{4}$, a remarkable achievement indẹed.

Diabetes mellitus complicates 2 to 3 percent of all pregnancies and 90 percent of these women have gestational diabetes (GDM) ${ }^{5}$. The incidence of diabetes in pregnancy in this centre has been previously put at 0.64 per 1000 deliveries per year ${ }^{\circ}$ and in Benin, also in Nigeria, $0.13 \%$ of deliveries ${ }^{?}$. Diabetes in pregnancy is unique because of the diversity of problems that can affect the embryo or fetus beginning right from conception ${ }^{8}$ and ending in an adverse maternal or fetal outcome ". The St. Vincent declaration of 1989 set, as a five-year target, the reduction of adverse pregnancy outcomes among diabetic women to a level equal to that among non-diabetic women ${ }^{10}$.

The objectives of this study were to determine the incidence of diabetes mellitus in pregnancy in this

Correspondence: Dr. A. Oladokun. Department of Obstetrics and Gynaecology. University College Hospital. Ihadan, Nigeria.

E-mail: soladokunaskannet.com 
centre, to assess the effect of maternal glucose control on the obstetric performance as well as perinatal outcome of pregnant diabetics managed at the University College Hospital, Ibadan.

\section{Materials and Methods}

The clinical records of all patients with diabetes mellitus in pregnancy that delivered at the University College Hospital, lbadan between the $1^{\text {st }}$ of January, 1991 and the $31^{\mathrm{st}}$ of December, 2000, a 10-year study period, were retrieved for analysis. The definition of gestational diabetes mellitus (GDM) used was 'carbohydrate intolerance first recognised during the index pregnancy' '. During pregnancy, having at least three of the four results in a 4-point blood sugar analysis within normal limits was interpreted as good glucose control.

Data on the booking status, maternal age and parity, past obstetric and gynaecologica! history, glucose control, pregnancy complications, fetal outcome and maternal outcome werc collected. The data collected were analysed using Epi-Info, version 6 statistical software packages. Frequency tables were generated and tests of association between variables were carried out using the chi-square test and a $p$-value of $<0.05$ was taken as significant

\section{Results}

During the 10-year review period, there were 8,487 deliveries in this hospital and 63 patients had diabetes mellitus in pregnancy giving an incidence rate of 0.74 per 1000 deliveries per year. Out of these $6.3 \mathrm{c}$ ases, a dequate records for a nalysis were obtained in 49 patients $(77.8 \%)$. The others could either not be traced or had insufficient information.

Of the patients studied, $31(63.3 \%)$ had pre-existing diabetes mellitus and $18(36.7 \%)$ had gestational diabetes mellitus. Forty-four patients $(89.8 \%)$ were booked for antenatal care and delivery in this centre and five $(10.2 \%)$ were seen for the first time in labour. The gestational age at booking ranged between 10 and 35 weeks. The maternal age range was 23 to 40 years (mean: 31.74 ; SD 8.68). Most of the patients $(77.5 \%)$ had parity less than 2 , while $10.2 \%$ of the patients were grandmultipara (Table 1) Ten (20.4\%) patients gave a history of previous feta] loss. Of these, $7(14.3 \%)$ had one or more previous spontaneous abortions, and 3 had a history of perinatal deaths.

The maternal weight ranged between $42.9-110.0 \mathrm{~kg}$ with a mean of 71.94 (SD: 25.4). The body mass index ranged between 19 and 42, with a mean of 28.59 (SD: 9.38 ).
Diabetic control was achieved by dietary measures alone or a combination of diet and insulin injections. Good control was achieved in $38(77.6 \%)$ of the patients. Eighteen $(36.7 \%)$ patients were controlled on diet alone and the remainder on a combination of dietary measures and insulin.

The gestational age at delivery ranged from 32 to 41 weeks. Five $(10.2 \%)$ patients delivered before the 36th week of gestation (three had induction of labour for intrauterine fetal death and the other two had premature rupture of fetal membranes).

\section{Table 1}

\section{Clinical Profile and Mode of Delivery of the 49 Diabetic Patients}

\section{Variable}

Booking Status
Booked
Unbooked

Maternal Age (years)

$21-25$

26-30

$31-35$

$36-40$

Maternal Parity

0

1

2

3

4

5

6

\section{Mode of Delivery}

Spontaneous Vertex

Elective Caesarean

Emergency Caesarean

\section{Number of \\ Patients (\%)}

$44(89.8)$

$5(10.2)$

$4(8.2)$

$18(36.7)$

$20(40.8)$

$7(14.3)$

$8(16.3)$

$15(30.6)$

$15(30.6)$

$3(6.1)$

$3(6.1)$

$3(6.1)$

$2(4.1)$

$31(63.3)$

$11(22.4)$

$7(14.3)$
In those undergoing caesarean section, indications included a history of at least one previous caesarean section in 10 patients while in one patient it was multiple pregnancy (twins) in a primigravida. One patient also had severe pre-eclampsia.

There was no statistically significant association between the type of labour and mode of delivery. There were 47 singletons and 2 sets of twins making a total of 51 babies. Both sets of twins were born alive and had good Apgar scores of 9 at 1 minute and 10 at 5 minutes. Live births occurred in 44 $(89.8 \%)$ of the patients, $4(8.2 \%)$ had stillbirths and one $(2 \%)$ had early neonatal death. The perinatal mortality rate (PMR) was $98 / 1000$ births. The PMR was significantly higher in women with poor diabetic control when compared with patients whose 
diabetic control was good ( $p=0.0043$ ). The birth weights ranged from 1.65 to $4.75 \mathrm{~kg}$. The mean birth weight was 3.37 (SD: $1.52 \mathrm{~kg}$ ). Ten babies (20.4\%) weighed $4 \mathrm{~kg}$ or more and were therefore considered macrosomic.

A mother who had poor blood glucose control had premature delivery, at 32 weeks, of a fresh stillborn infant with encephalocoele. The heaviest baby weighed $4.75 \mathrm{~kg}$, had shoulder dystocia and was delivered vaginally with the aid of the McRobert manoeuvre, following induction of labour for poor glucose control. Three women who delivered infants between $3.45-4.75 \mathrm{~kg}$ had perineal tears. A patient who had emergency lower segment caesarean section following poor progress in labour had poor blood sugar control with insulin and had early neonatal death of a $4.1 \mathrm{~kg}$ infant. She also developed post-operative wound sepsis.

There was no significant difference in the birth weight and fetal outcome in patients with preexisting and gestational diabetes. The important predictor of outcome was the level of diabetic control. With good control, there was a better 5minute Apgar score, an important prognostic marker for fetal outcome. No maternal death was recorded.

\section{Discussion}

In 1989 , the St. Vincent declaration stated as a five year goal that the "outcome of diabetic $p$ regnancy should approximate that of the non-diabetic pregnancy"10. The last study on diabetes in pregnancy in this country that we are aware of was published 16 years ago and was conducted in this institution ${ }^{6}$. We decided to see if there has been an improvement in the outcome of pregnancies in these patients and to see if the goal of the St. Vincent declaration is being met in Nigeria.

The incidence of diabetes mellitus in pregnancy of 0.74 per 1000 deliveries per year in this study is an increase over the previous rates of 0.31 reported in $1966^{\prime \prime}$ and 0.64 reported in $1985^{\circ}$ from this centre. There has therefore continued to be an increase in incidence. In $B$ enin in 1982 , the rate $w$ as $0.13 \%$. Diabetes mellitus complicates 2 to 3 percent of all pregnancies generally ${ }^{5}$.

\section{References}

1. American College of Obstetrics \& Gynecology. Diabetes and pregnancy. Int J Gynecol Obstet. 1995; 48: 331-339.

2. Rosenn BM, Miodovnik M. Glycemic control in the diabetic pregnancy: is tighter always better? $J$ Matern Fetal Med. 2000; 9: 29-34.
From our study, only $36.7 \%$ of the patients had gestational diabetes, a much lower proportion than the $90 \%$ reported from other places, which makes it the most common complication seen in obstetrics today ${ }^{5}$. Good control was achieved in $77.6 \%$ of our patients during the index pregnancies. This was amply reflected in the fetal outcome, especially the mean birth weight of $3.37 \mathrm{~kg}$.

The mode of delivery shows a high degree of intervention. In pregnancies complicated by diabetes mellitus, the major concerns during the $3^{\text {rd }}$ trimester are perinatal loss and the potential for birth trauma associated with fetal macrosomia. Elective delivery, either by induction of labour or by elective caesarean section rather than expectant management at term is recommended ${ }^{12}$. The caesarean section rate in these patients of is slightly lower than what was previously reported in pregnant diabetics in this centre ${ }^{6}$.

Poorly-controlled diabetes in pregnancy is often associated with a high fetal morbidity and mortality. It is also associated with complications such as congenital malformations, fetal m acrosomia, largefor-date $b$ abies, unexplained intrauterine death and neonatal hypoglycaemia. The patients who had macrosomia in this study had poor control. One of these patients had premature delivery of a $4.1 \mathrm{~kg}$ fresh stillborn infant with encephalocoele despite booking early at 10 weeks. The perinatal mortality rate of $9.8 \%$ found is lower than the $10.8 \%$ and $24 \%$ previously reported from here in $1986^{\circ}$ and $1966^{\prime 1}$ respectively, and the $16.7 \%$ reported from Benin in $1982^{7}$. This can be attributed to the continued improvement in the care and control of these patients. The very low incidence of maternal morbidity and the absence of maternal mortality is further evidence of this. Maternal mortality and morbidity in diabetic patients is still higher than in non-diabetic pregnancies ".

Diabetic pregnancy remains a high-risk state, with perinatal mortality and fetal malformation rates much higher than in the general population. Further improvement in the management of these patients is needed. Preconception control, early antenatal booking and good control in pregnancy will go a long way toward achieving this.

3. Spellacy WN. Diabetes mellitus and pregnancy. In: Scott JR et al (eds). Danforth's Obstetrics and Gynecology, 7th edition. New York, JB.Lippincott Company, 1994: 343-350.

4. Huddle KRL. Diabetes in pregnancy. Diabetes Int. 1999: 9: 53- 55. 
5. Onofriescu M. The diagnosis of gestational diabetes. Revista Medico-Chirurgicala a Societaff: de M edici si Naturalistic Din lasi $1998 ; 102: 41-48$.

6. Otolorin EO, Famuyiwa OO, Dawodu AH, Adelusi, B. Reproductive performance following active management of diabetic pregnancies at the University College Hospital, Ibadan, Nigeria. Afr $J$ Med Med Sci. 1985; 14: 155-160.

7. Diejomaoh FME, Asuquo EEJ, Omene JA AbuBakare A. An active approach to the management of diabetes mellitus in pregnancy in Nigeria. Trop $J$ Obstet Gynaecol, 1982; 3: 7-12.

8. Schwartz R, Teramo KA. Effects of diabetic pregnancy on the fetus and newborn. Sem Perinat, $2000 ; 24: 120-135$.
9. Griffin ME, Coffey M, Johnson H, Scanlon P, Foley M, Stronge J, O'Meara NM, Firth RG. Universal vs. risk factor-based screening for gestational diabetes mellitus: detection rates, gestation at diagnosis and outcome. Diabetic Med, 2000; 17: 26-32.

10. Workshop Report. Diabetes care and research in Europe: The Saint Vincent Declaration. Diabet. Med, 1990; 7: 360.

11. Kinnear TWG, Ojo OA. Pregnancy and diabetes in Nigeria. West Afr Med J, 1966; 15: 146-148.

12. Boulvain $M, S \tan C$, Irion $O$. Elective delivery in diabetic pregnant women. Cochrane Database of Systemic Reviews, 2000; (2): CD001997. 